University of Nebraska - Lincoln

DigitalCommons@University of Nebraska - Lincoln

April 1993

\title{
A Longitudinal Investigation of the Relationship Between Educational Investment and Adolescent Sexual Activity
}

Christine McCauley Ohannessian

Pennsylvania State University

Lisa J. Crockett

University of Nebraska-Lincoln, ecrockett1@unl.edu

Follow this and additional works at: https://digitalcommons.unl.edu/psychfacpub

Part of the Psychiatry and Psychology Commons

McCauley Ohannessian, Christine and Crockett, Lisa J., "A Longitudinal Investigation of the Relationship Between Educational Investment and Adolescent Sexual Activity" (1993). Faculty Publications,

Department of Psychology. 251.

https://digitalcommons.unl.edu/psychfacpub/251

This Article is brought to you for free and open access by the Psychology, Department of at DigitalCommons@University of Nebraska - Lincoln. It has been accepted for inclusion in Faculty Publications, Department of Psychology by an authorized administrator of DigitalCommons@University of Nebraska - Lincoln. 


\title{
A Longitudinal Investigation of the Relationship Between Educational Investment and Adolescent Sexual Activity
}

\author{
Christine McCauley Ohannessian \\ Lisa J. Crockett \\ Pennsylvania State University
}

\begin{abstract}
The relation between educational investment and sexual behavior was examined longitudinally in a sample of 479 rural adolescents. Surveys were administered to the subjects twice - once when they were in the 8th, 9th, and 10th grades, and again 2 years later when they were in the 10th, 11th, and 12th grades. Results indicated that among girls, educational investment predicted sexual activity, with academic grades in school significantly predicting reported frequency of sexual activity 2 years later. In contrast for boys, sexual involvement predicted later educational investment, particularly involvement in academic activities. These findings suggest different developmental patterns for boys and girls. For girls, academic involvement may limit their sexual activity. However sexual activity does not seem to reduce educational involvement. In contrast, sexual activity is associated with less involvement in academic activities for boys. The possible reasons for these gender differences are discussed.
\end{abstract}

The study was supported by the Office of Adolescent Pregnancy Programs, grant \# APR000933 to J. R. Vicary. A version of this article was presented at the biennial meeting of the Society for Research in Child Development, Seattle, Washington, April 18-20, 1991. We gratefully acknowledge the assistance of the staff of the Rural Adolescent Development Study, as well as the adolescents and schools who participated in the study.

In recent years, adolescent sexuality has become a source of increasing social concern because of its link to adolescent pregnancy, the risk of contracting sexually transmitted diseases, and to the possible negative impact of early sexuality on other aspects of adolescent development (Hofferth, 1987). To date, an extensive body of research has accumulated on the correlates and predictors of adolescent sexual activity. A number of studies have indicated that domains such as socioeconomic status (SES), family structure and relationships, pubertal maturation, and various personality and behavioral characteristics are related to the timing and frequency of adolescent sexual activity (Chilman, 1986; Hofferth, 1987). 
An additional correlate of sexual activity cited by several researchers is the adolescents' investment in their own education. Typically, a negative association has been reported between academic involvement and adolescent sexual activity (Chilman, 1986). The reason for this negative association however, is not clear. One hypothesis is that a greater investment in education decreases the likelihood of early sexual activity by providing an alternative reward structure or an alternative set of activities (e.g., Miller \& Sneesby, 1988). Such a position is consistent with social control theory (Hirschi, 1969). According to this model, strong bonds to conventional institutions reduce the likelihood that an individual will engage in norm-breaking or deviant activities. Bonds consist of attachment to conventional others (who would disapprove of deviant activities), involvement in conventional activities (which reduce the time and opportunity for deviant activities), investment in conventional institutions (having a stake in the system that one would not wish to jeopardize through deviant activity), and belief in conventional values and rules (which proscribe deviant behavior). Clearly, the adolescent's school constitutes such a conventional institution. In contrast, adolescent sexual activity, although common, violates social norms regarding appropriate adolescent behavior and in this sense represents a form of social transgression or deviance (Jessor \& Jessor, 1977). Thus there is a theoretical basis for the hypothesis that academic involvement reduces the probability of adolescent sexual activity.

An alternative hypothesis is that early involvement in sexual activity decreases adolescents' academic performance and involvement by drawing them into more immediately rewarding activities that may take time away from academic pursuits. Billy, Lansdale, Grady, and Zimmerle (1988) noted, for example, that adolescents who lose their virginity may spend a greater amount of time thinking about and participating in sexual activities. If so, such behavior could reduce the time that these adolescents spend in academic activities. In addition, early sexual involvement may cause young people's priorities to shift, perhaps increasing their interest in early marriage and parenthood at the expense of their commitment to an extended education.

Both of these hypothesized processes represent plausible developmental mechanisms linking adolescents' investment in school to their sexual activity. They have, however, very different implications for the understanding of adolescent development. Consequently, it becomes important to disentangle these processes: To determine whether educational investment predicts later sexual activity, whether early sexual activity predicts later educational investment, or whether both processes occur. To date, little research has addressed this issue. Most of the studies of educational investment and sexual activity have been 
cross-sectional in design. Although they have demonstrated a negative relationship between educational variables and sexual activity, such studies cannot address antecedent-consequent relationships (Miller \& Simon, 1974; Miller \& Sneesby, 1988). Longitudinal data are needed in order to address this issue.

Only a few prior studies have examined the relationship between educational variables and adolescent sexual activity over time. In a sample of White metropolitan adolescents, Alwin (1986) used structural equation modeling to examine the relationship of educational plans and academic grades in school to sexual activity. He found that boys with higher educational plans were less likely to report being sexually active later in adolescence than boys with lower educational plans. Academic grades in school, however, did not predict sexual activity for boys, and neither plans nor academic grades in school predicted sexual activity among girls. On the other hand, early sexual activity negatively predicted later educational plans for both boys and girls.

In a second study, Billy and his associates (Billy et al., 1988) examined the relationship between adolescent nonvirginity and later school performance and educational plans among White adolescents residing in a metropolitan area. Billy et al. (1988) found that early sexual intercourse negatively predicted the importance that girls attached to attending college 2 years later. In addition, early sexual intercourse negatively predicted later school performance among boys. The influence that educational variables had on later sexual activity was not examined.

These prior longitudinal studies provide some support for each of the hypothesized processes, although there were inconsistencies concerning which educational variables related to sexual activity, particularly for boys. The one consistent finding seemed to be the negative relationship between early sexual activity and later educational plans among girls. Importantly, the previous studies have suggested that the linkages between educational variables and sexual activity may differ for girls and boys. It should be noted, however, that the influence of educational variables on later sexual activity was examined only in one study (Alwin, 1986). In addition, in the Alwin study the educational variables were measured retrospectively, introducing the problem of recall bias and potentially confounding the issue of antecedent-consequent relations. Furthermore, these two longitudinal studies included only adolescents from metropolitan areas. Longitudinal research examining these domains with adolescents from rural areas has been relatively neglected.

The present study provided a more comprehensive investigation of the relationship between adolescent educational investment and sexual activity by 
employing two waves of longitudinal data collected on a sample of rural adolescent boys and girls over a 2-year period. Using these data, the following questions were addressed: (a) What is the nature of the relationship between educational investment and sexual activity over time? and (b) Does the relationship between educational investment and sexual activity differ for boys and girls?

\section{METHOD}

\section{Subjects and Design}

The present study included 479 adolescents (49\% girls and 51\% boys) who were participants in a larger longitudinal study of rural adolescent development. The subjects were White and resided in a geographically contained rural school district in the Mid-Atlantic region of the eastern United States. The combined population of the towns included in the district was 16,411 in 1980 (U.S. Department of Commerce, 1980).

Most of the subjects were from either lower- or middle-class families. The median income in the community was $\$ 14,500$ per year in 1980 (U.S. Department of Commerce, 1980). Additionally, 13\% of the population reported having an income below the poverty level. The most common adult occupations in the community were laborers and technical/clerical workers (U.S. Department of Commerce, 1980).

The total sample included almost all students in the district who were in the seventh, eighth, and ninth grades at the beginning of the study. The average age of the subjects was 13.73 years at the first time of measurement. These subjects have been followed annually for 5 years, through surveys conducted each fall. The present study used data from the second and the fourth surveys (hereafter referred to as Time 1 and Time 2). Only subjects who were present at both times of measurement were included $(77 \%$ of the total sample).

It should be noted that these subjects differed slightly from the adolescents who did not participate at both times of measurement. For boys, when sexual activity, educational plans, academic activities, and academic grades in school were compared, the mean level of participation in academic activities was significantly higher in the longitudinal sample than in the nonlongitudinal sample $(t[77]=-2.03, p<.05)$. However, the boys' longitudinal and nonlongitudinal samples did not differ significantly in their educational plans, grades in school, and reported frequency of sexual activity. In addi- 
tion, when the girls' longitudinal and nonlongitudinal samples were compared, none of the educational variables or sexual activity differed significantly across samples.

\section{Measures}

The annual survey consisted of items that tap the following domains: cognitive functioning, self-esteem, family and peer relationships, future plans and expectations, family characteristics, activities and social behaviors, and emotional tone. Variables pertaining to educational investment and sexual behavior were used in this study.

\section{Educational Investment}

Three educational variables were used to measure educational investment: Educational plans, academic grades in school, and participation in academic activities. To assess educational plans, the subjects were asked, "How far do you plan to go in school?" Adolescents responded on a 6-point scale ranging from 1 = some high school to 6 = graduate or professional training. As an index of reliability, stability coefficients for the educational variables were calculated. These coefficients for educational plans were fairly stable over time. For example, between Time 1 and Time 2, correlations between educational plans were $.52(p<.001)$ and $.57(p<.001)$, for girls and boys, respectively.

Students also reported their typical academic grades in school. Response categories for this question ranged from $1=$ mostly $F$ s to $8=$ mostly As. Selfreported school grades were used because school records were not available. However, self-report measures of grades appear to be reasonably accurate (Crockett, Schulenberg, \& Petersen, 1987). Stability coefficients from the present sample indicated that this variable also was relatively stable. Between Time 1 and Time 2, the correlations for academic grades in school were $.60(p$ $<.001)$ and $.46(p<.001)$, for girls and boys, respectively.

Subjects were also asked how often they participated in academic activities, such as doing homework, school projects, participating in science fairs, and reading books. Responses were coded on a 6-point scale ranging from 1 $=$ never to $6=$ many times daily. This variable was not as stable as those discussed previously. The stability coefficients between Time 1 and Time 2 for girls and boys, respectively, were $.42(p<.01)$ and $.41(p<.001)$. 


\section{Sexual Activity}

A measure of sexual activity was included as part of a larger behavior questionnaire in the surveys. Subjects were asked how frequently they had been sexually active ("had sex"). This item was coded on a 6-point scale where 1 = never happened and 6 = happens almost every day. Although sexual activity referred to specifically "having sex," it is possible that some adolescents may have interpreted the question as including behaviors besides sexual intercourse. To address this issue several validity checks were conducted. First, the correlations between the sexual activity item and two other items measuring sexual behaviors were examined. These two items referred, respectively, to the frequency of "having necked or kissed" and to the frequency of "having been touched on a private part of the body." Because these items also represent sexual behaviors, it was expected that substantial correlations between them and the sexual activity item would be seen. At the same time, extremely high correlations would suggest that the three items were interpreted as meaning the same thing. Such a lack of discrimination would raise concerns about measurement validity.

At Time 2, boys' frequency of sexual activity correlated $.69(p<.001)$ with frequency of necking and kissing and $.68(p<.001)$ with frequency of being touched on a private part of the body. Girls' reported frequency of sexual activity at Time 2 correlated $.66(p<.001)$ with frequency of necking and kissing and with frequency of being touched on a private part of the body. Thus the correlations, although substantial, were not extremely high.

In a second set of analyses, the frequency distributions of the three sexual behavior items were compared. The three items represent a continuum of progressively intimate behaviors, reflecting the typical sexual sequence shown by White adolescents (Smith \& Udry, 1985). Therefore, it was expected that kissing would be more prevalent than touching, and touching would be more prevalent than "having sex." The percentage of adolescents reporting each sexual behavior confirmed this expectation.

More adolescents reported that they had kissed someone than had "been touched" at each time of measurement. Likewise, a greater percentage of the subjects reported having been touched sexually, than having "had sex" at both times of measurement. Finally, it was expected that individual adolescents would exhibit the same sequence of behaviors. That is, adolescents who reported having been touched should have reported also having kissed or necked, and adolescents who reported having "had sex" should have reported also having kissed or necked and having been touched. Although deviations from this pattern are possible, they should be relatively rare. 
To examine this issue, crosstabs were run among the sexual behavior items at Time 2, with each variable dichotomized to reflect presence or absence of the behavior. Overall, $92 \%$ of the boys and $93 \%$ of the girls conformed to the expected pattern. Only $2 \%$ of the boys and 3\% of the girls reported having been touched without having kissed, and only $5 \%$ of the boys and $4 \%$ of the girls reported having "had sex" without having been touched. Finally, only $1 \%$ of the boys and none of the girls reported that they had "had sex" without having necked or kissed. These patterns indicate that the adolescents in the present study correctly interpreted the questions about sexual behavior and accurately discriminated among the three behaviors, supporting the validity of the sexual activity measure.

\section{SES and Age}

Previous research has reported a significant relationship between SES and adolescent sexual activity (Chilman, 1986; Hofferth, 1987; Zelnik, Kantner, \& Ford, 1982). In addition, SES has been found to predict educational variables (e.g., educational plans; Danzinger, 1983; Sewell \& Shah, 1968). Therefore, SES was included as an additional predictor variable.

The measure of SES was the average of the mothers' and the fathers' educational attainment as reported by the adolescents. This measure was chosen because parents' educational attainment appears to be one of the most important and stable indicators of SES (Hofferth, 1987). At each time period, adolescents were asked how far each parent had gone in school. Responses were coded from 1 = grade school through $6=$ post college. Because the response scale was slightly altered between Waves 2 and 3 of data collection, ${ }^{1}$ stability coefficients were calculated on data from Waves 3 and 4 . These coefficients were $.84(p<.001)$ and $.87(p<.001)$, for girls and boys, respectively.

The adolescent's age was also included as a second background variable. It is evident that sexual experience among adolescents increases almost linearly with age (Hofferth, 1987). In addition, age may also influence educational variables measured during adolescence, especially educational plans. In the present study, subjects were asked to report their birthdate as part of the survey. Age was calculated in months and then converted to years to simplify presentation.

\section{Procedure}

Each fall, subjects were administered a survey during school hours by project personnel. Parental consent forms were distributed to all students in 
the three grade cohorts. Students whose parents did not agree to their participation were not included in the study. Data collection involved group testing, with approximately two testers per classroom of students. Surveys were completed in either the homeroom, the cafeteria, or the English class of the subject's school depending on the year that the survey was administered. The questionnaire took approximately 1 hour to complete.

\section{RESULTS}

\section{Descriptive Statistics}

Item frequencies, means, and standard deviations were calculated for all variables at Time 1 and Time 2. The reported prevalence of sexual activity increased over time, as would be expected. At Time 1 (when the subjects were in the 8th, 9th, and 10th grades), $27 \%$ of the girls and $48 \%$ of the boys reported having been sexually active. At Time 2 (when the subjects were in the 10 th, 11 th, and 12 th grades), $64 \%$ of the girls and $73 \%$ of the boys had "had sex."

In contrast, the means of the educational variables were stable across time. For example, at Time 1, the means for academic grades in school were 6.29 and 6.00 , for girls and boys, respectively. At Time 2, the respective means were 6.29 and 5.90 .

\section{Bivariate Analyses}

Because past research has demonstrated an inverse association between educational variables and sexual activity among adolescents from metropolitan areas, Pearson product-moment correlations were computed (concurrently and longitudinally) to attempt to replicate this finding in the present sample of rural adolescents. The correlations for boys and girls are presented in Table 1.

Girls. All of the correlations between the educational variables and sexual activity were negative for girls. In addition, $92 \%$ of the correlations between the educational variables and sexual activity were significant. As Table 1 illustrates, all of the correlations between academic activities and sexual activity and between grades in school and sexual activity were significant. The only correlation that was not significant for girls occurred between frequency of sexual activity at Time 1 and grades in school at Time 2. Overall, correlations were small to moderate, ranging from -.13 to -.36 . 


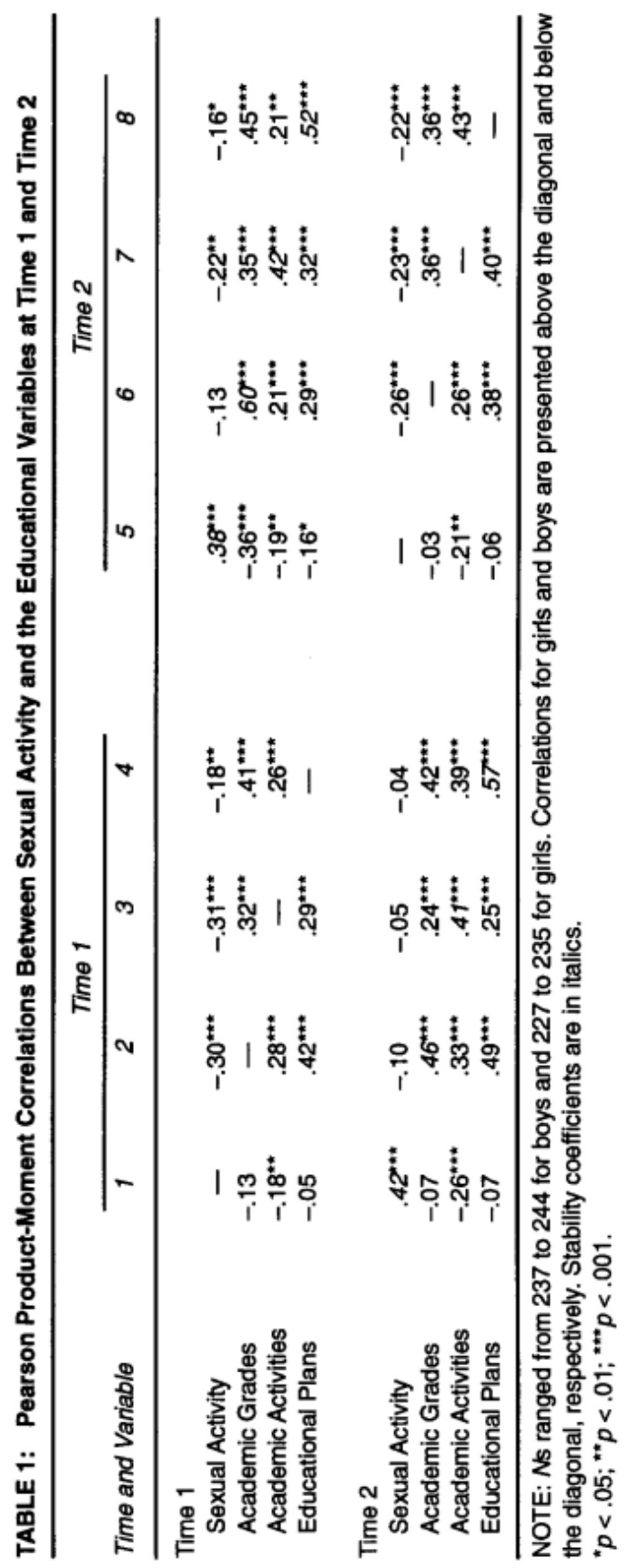


TABLE 2: Regression Models Predicting Adolescent Sexual Activity from the Demographic Control Variables and Prior Educational Variables

\begin{tabular}{lccccc}
\hline & \multicolumn{2}{c}{ Girls'Models } & & \multicolumn{2}{c}{ Boys'Models } \\
\cline { 2 - 3 } \cline { 5 - 6 } Predictors & 1 & 2 & & 1 & 2 \\
\hline Age & $.03^{\star}$ & $.03^{*}$ & & .02 & .02 \\
Parents' education & -.13 & -.06 & & .01 & .01 \\
Prior sexual activity & $.65^{\star \star}$ & $.49^{\star *}$ & & $.54^{\star \star}$ & $.54^{\star \star}$ \\
Grades & & $-.40^{\star \star}$ & & & n.s. \\
Plans & & n.s. & & n.s. \\
Academic activities & & n.s. & & n.s. \\
Model R-square & $.20^{\star \star}$ & $.28^{\star \star}$ & & $.22^{* \star}$ & $.22^{\star *}$ \\
\hline
\end{tabular}

NOTE: Unstandardized regression coefficients are provided.

n.s. $=$ variable did not meet the .10 significance level required for model entry.

${ }^{\star} p<.01 ;{ }^{\star *} p<.001$.

Boys. Similar to the results obtained for girls, all of the educational variables were negatively correlated with sexual activity for boys. In contrast to the girls, however, few of these relationships (25\%) were significant. The only significant associations were between academic activities and sexual activity. Correlations for boys ranged from -.03 to -.26 .

\section{Regression Analyses}

A series of hierarchical regression models was conducted to determine the predictive relationships between sexual activity and the educational variables over time. ${ }^{2}$ Two models were analyzed for each relationship examined (e.g., grades in school at Time 1 and sexual activity at Time 2). The initial model included parents' educational attainment, age, and the dependent variable measured previously as predictor variables. The subsequent model included these variables along with the predictor variable of primary interest (either educational variables or sexual activity, depending on the analysis). This model enabled us to assess the effect of the primary predictor variable(s), net of the "control" variables.

For each gender, the educational variables measured at Time 2 were regressed on sexual activity measured at Time 1; similarly, sexual activity assessed at Time 2 was regressed on the educational variables measured at Time 1. In this way, it was possible to examine both sets of predictive relationships. Results are summarized in Tables 2 and 3. Table 2 summarizes the results for models predicting sexual activity from the educational variables, and Table 3 shows the models predicting the educational variables from sexual activity. 


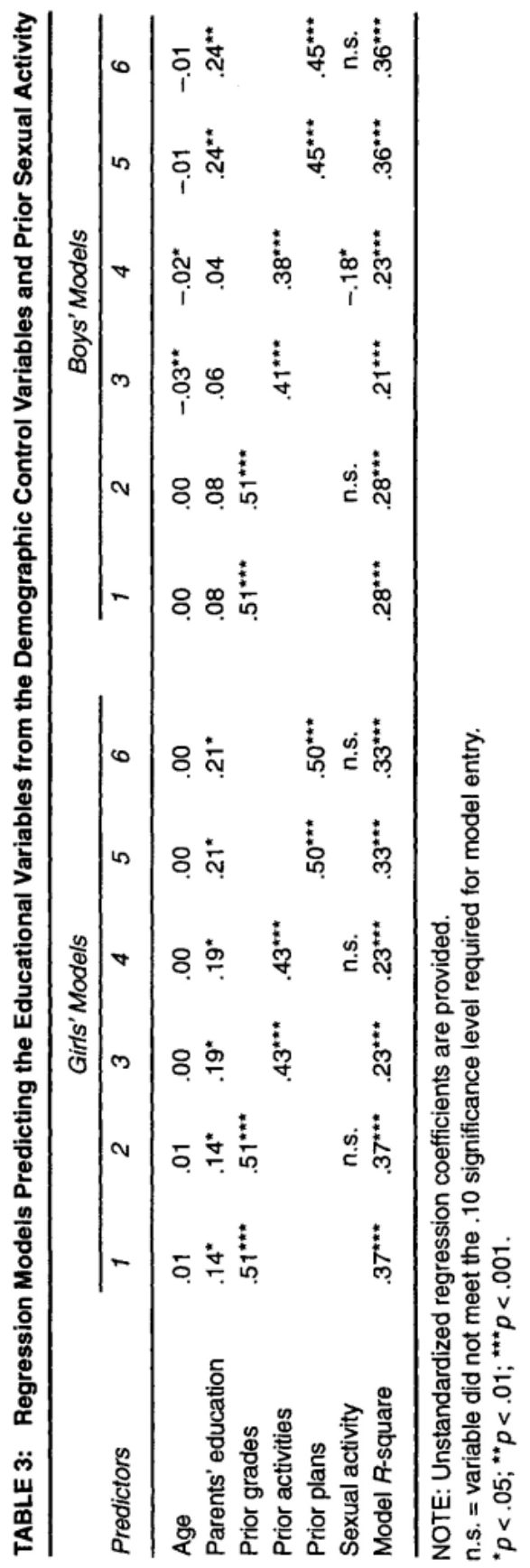


Girls. For girls, both age and prior sexual activity significantly predicted sexual activity at Time 2 (see Table 2). In addition, grades in school significantly predicted sexual activity, net of the priors, but plans and academic activities did not. In contrast, Table 3 shows that parents' education and the prior educational variables significantly predicted the educational variables, however sexual activity at Time 1 failed to predict the educational variables at Time 2, after the variance from the "controls" was accounted for. These findings support the hypothesis that educational investment (particularly grades in school) predicts later frequency of sexual activity among girls.

Boys. For boys, prior sexual activity predicted later sexual activity, however none of the educational variables significantly predicted sexual activity once the background variables and prior sexual activity were included in the regression models (see Table 2).However, when the educational variables were predicted from sexual activity, a significant relationship emerged. As Table 3 illustrates, reported frequency of sexual activity measured at Time 1 significantly predicted boys' participation in academic activities at Time 2 , even after the variance from the "control" variables was accounted for. These results provide support for the hypothesis that sexual activity predicts later educational investment among boys.

\section{DISCUSSION}

Previous research has demonstrated that educational investment is inversely related to sexual activity during adolescence (e.g., Jessor, Costa, Jessor, \& Donovan, 1983; Miller \& Simon, 1974; Miller \& Sneesby, 1988). However, there are few longitudinal examinations of this relationship in the literature. Additionally, studies that have focused on the relationship between educational investment and sexual activity have tended to examine adolescents residing in metropolitan areas (e.g., Alwin, 1986; Billy et al., 1988). Therefore, the primary purpose of the current study was to examine the relationship between adolescent educational investment and sexual activity in a group of rural adolescents over time.

Because educational variables have been found to be negatively associated with sexual activity in previous cross-sectional studies on adolescents from metropolitan areas, the present correlational analyses were conducted to determine if this relationship was valid also for adolescents from rural areas. As expected, a consistent inverse relationship between the educational variables 
and sexual activity was found both for girls and boys. This is in accordance with assertions that conventional behaviors (e.g., educational or religious investment) and problem behaviors (e.g., early sexual involvement) are incompatible (Billy et al., 1988; Jessor et al., 1983). Specifically, a focus on activities associated with studying and getting good grades in school may reduce the opportunity for sexual involvement, either because of time constraints or because of associations with more conventional peers. In addition, an educational focus may provide alternative rewards that may preoccupy some adolescents. Finally, an educational focus may reflect other personal characteristics (e.g., the ability to delay gratification and greater conventionality) which in turn may make sexual involvement less likely. Indeed, Jessor and his colleagues found that adolescents who remained virgins into young adulthood were more conventional than their peers as adolescents (Jessor et al., 1983).

In addition to concurrent analyses, longitudinal regression analyses were conducted also to begin to disentangle the direction of effects between the educational variables and sexual activity for girls and boys. For girls, academic grades in school significantly predicted reported frequency of sexual activity 2 years later, but sexual activity did not significantly predict any of the educational variables.

These findings contrast with those of prior longitudinal studies. The Alwin study (1986) and the Billy et al. study (1988) indicated that sexual activity predicts educational investment for girls, with no evidence of a reverse effect. One explanation for this discrepancy is that the sample in the present study included only adolescents who resided in a rural area, whereas the samples in the other studies were drawn from metropolitan areas. Perhaps, sexual activity and educational investment are more compatible for girls who live in metropolitan areas than for girls who live in rural areas because sexual activity may be perceived to be less deviant in urban settings. Indeed, researchers have found that girls who live in metropolitan areas are more sexually active than girls who live in rural areas, suggesting that sexual activity might be perceived as less deviant among girls living in metropolitan areas (Devaney \& Hubley, 1981).

The results obtained for boys yielded a different picture than those found for girls. For boys, none of the educational variables significantly predicted sexual activity. However, sexual activity significantly predicted later participation in academic activities. These results are similar to those found in the Alwin study (1986) and the Billy et al. (1988) study. Sexual activity was found to predict later educational investment for boys in both of these studies. In the Alwin study, initiation of sexual activity was found to predict boys' ed- 
ucational plans, and in the Billy et al. study, initiation of sexual activity predicted boys' academic grades in school. Only one educational variable, educational plans, was found to significantly predict sexual activity for boys (Alwin, 1986). The data from these prior studies and the present study suggest that among adolescent boys, initiation of sexual activity and frequency of sexual activity predict educational investment more than the reverse.

It is interesting to note that when the relationship between educational investment and sexual activity was examined in the present study, different results emerged for boys and girls. The fact that educational investment (as indexed by grades in school) significantly predicted sexual activity for girls, but not for boys, supports the interpretation that rural girls who are invested in their education may perceive sexual activity as threatening to their futures in a way that boys do not. This would not be surprising because if a pregnancy occurs, it is usually the female who has to make educational and career sacrifices. Additionally, boys from rural areas may not perceive sexual activity and educational investment to be as incompatible as do girls from rural areas because sexual activity appears more normative for them (in the current sample, adolescent boys reported more frequent sexual activity than girls at both times of measurement).

The results obtained in this study have important implications for prevention. If involvement in sexual activity predicts later participation in academic activities for boys, and participation in academic activities is related to later educational and occupational success, then early involvement in sexual activity may deleteriously affect a boy's future. A boy who becomes involved in sexual activity and consequently less involved in "conventional" activities (e.g., participation in academic activities) may close off important educational options. Future research should attempt to document the change in attitudes and expectations that would presumably accompany this decline in educational investment.

The results from the present study also indicated that high educational investment may lower the frequency of sexual activity for girls. This in turn decreases the likelihood of an unplanned pregnancy. Although it is not known whether girls' educational investment acts as a deterrent to early sexual involvement (e.g., by focusing attention on alternate goals and activities), or reflects underlying personality variables (e.g., conventionality), the present results are at least consistent with programs that seek to prevent adolescent pregnancy by enhancing girls' academic achievement and aspirations for their future (Hayes, 1987). Future research should attempt to specify the mechanisms by which educational investment may deter early sexual activity for girls. 


\section{NOTES}

1. At Wave 3 and Wave 4 of data collection, the response scale was expanded to include an intermediate score for technical training beyond high school. However, the response scale at Wave 3 and Wave 4 was recoded to correspond to that at Wave 1 and Wave 2.

2. Model-fitting analyses using LISREL 7 were also computed in order to more precisely examine the predictive relationship between the educational variables and sexual activity. However, because these analyses yielded nearly identical beta estimates, the hierarchical regression models were presented for the sake of simplicity.

\section{REFERENCES}

Alwin, D. (1986).Adolescent sexuality and educational achievement expectations. Unpublished manuscript. Ann Arbor: University of Michigan, Institute for Social Research and Department of Sociology.

Billy, J. O. G., Lansdale, N. S., Grady, W. R., \& Zimmerle, D. M. (1988). Effects of sexual activity on adolescent social and psychological development. Social Psychology Quarterly, 51, 190-212.

Chilman, C. (1986). Some psychological aspects of adolescent sexual and contraceptive behaviors in a changing American society. In J. B. Lancaster \& B. A. Hamburg (Eds.), School-age pregnancy and parenthood (pp. 191-217).New York: Aldine de Gruyter.

Crockett, L. J., Schulenberg, J. E., \& Petersen, A. C. (1987). Congruence between objective and self-report data in a sample of young adolescents. Journal of Adolescent Research, 2, 383-392.

Danzinger, N. (1983). Sex related differences in aspirations of high school students. Sex Roles, 9, 683-695.

Devaney, B. L., \& Hubley, K. S. (1981). The determinants of adolescent pregnancy and childbearing. Final Report to the National Institute of Child Health and $\mathrm{Hu}-$ man Development. Washington, DC: Mathematica Policy Research.

Hayes, C. D. (Ed.). (1987). Risking the future: Adolescent sexuality, pregnancy, and childbearing. Washington, DC: National Academy Press.

Hirschi, T. (1969). Causes of delinquency. Berkeley: University of California Press.

Hofferth, S. L. (1987). Influences on early sexual and fertility behavior. In C. D. Hayes (Eds.), Risking the future: Adolescent sexuality, pregnancy, and childbearing (Vol. 2, working papers, pp. 7-35). Washington, DC: National Academy Press.

Jessor, R., \& Jessor, S. (1977). Problem behavior and psychosocial development: A longitudinal study of youth. New York: Academic Press. 
Jessor, R., Costa, F., Jessor, S. L., \& Donovan, E. (1983). Time of first intercourse: A prospective study. Journal of Personality and Social Psychology, 44, 608-626.

Miller, B. C., \& Sneesby, K. R. (1988). Educational correlates of adolescents' sexual attitudes and behavior. Journal of Youth and Adolescence, 17, 521-530.

Miller, P. Y., \& Simon, W. (1974). Adolescent sexual behavior: Context and change. Social Problems, 22, 58-76.

Sewell, W. H., \& Shah, V. P. (1968). Social class, parental encouragement and educational aspirations. American Journal of Sociology, 13, 559-572.

Smith, E., \& Udry, J. (1985). Coital and non-coital sexual behaviors of White and Black adolescents. American Journal of Public Health, 75, 1200-1203.

U.S. Department of Commerce. (1980). Characteristics of the population and general social and economic characteristics of Pennsylvania. Washington, DC: Author.

Zelnik, M., Kantner, J., \& Ford, K. (1982). Adolescent pathways to pregnancy. Beverly Hills, CA: Sage. 